\title{
Análise econômica da ovinocultura: estudo de caso na Metade Sul do Rio Grande do Sul, Brasil
}

\author{
Economic analysis of sheep production: a case study in the south region of \\ Rio Grande do Sul, Brazil
}

\author{
João Garibaldi Almeida Viana' ${ }^{\mathrm{I}}$ Vicente Celestino Pires SilveiraII
}

\section{RESUMO}

O presente trabalho tem como objetivo verificar os custos de produção e os seus componentes e a rentabilidade da produção ovina na Metade Sul do Rio Grande do Sul. A análise econômica de sete produtores teve a duração de 12 meses, compreendendo o período de agosto de 2006 a julho de 2007. Os dados mensais levantados consistem em todas as despesas e receitas e os valores referentes aos produtos consumidos nas propriedades. Foram realizados inventários patrimoniais e do rebanho ovino para o cálculo de depreciação e evolução dos ativos físicos. Os custos foram segmentados em variáveis, fixos, operacionais e totais. Indicadores econômicos foram formulados a fim de verificar a rentabilidade da atividade. Os custos variáveis e os de oportunidade foram as categorias que mais impactaram a formação do custo total. Dentro do custo operacional destaca-se o referente à mão-deobra, sendo o grupo de custo que mais onera a produção ovina. A ovinocultura é uma atividade rentável, que é determinada pelo saldo positivo dos indicadores de margem bruta e renda operacional agrícola. Entretanto, a margem líquida apresentou valores negativos em todas as propriedades analisadas.

Palavras- chave: custos de produção, ovinos, rentabilidade.

\section{ABSTRACT}

The goal of this study is to examine the production costs and profitability of the sheep raising sector in the south of Rio Grande do Sul. The economic analysis included seven sheep farms throughout 12 months, between August of 2006 and July of 2007. Expenses, revenue and value of products consumed in the farm were measured monthly. Depreciation and physical assets were calculated based on patrimony and breeding stock inventory. Costs were divided in variable, fixed, operational and total. Economic indicators were computed to evaluate sheep production profitability. Results showed that variable and opportunity costs had the largest impact on total costs. In terms of operational costs, labor were the largest expense for sheep raising farms. Overall, sheep production is a profitable activity, as indicated by positive gross margins and operational revenue indicators. However, net margins were negative across all farms included in the study.

Key words: production costs, sheep, profitability.

\section{INTRODUÇÃO}

A ovinocultura é uma das principais atividades pecuárias desenvolvidas no Estado do Rio Grande do Sul. Seu estabelecimento como exploração econômica se deu no começo do século XX, com a valorização da lã no mercado internacional e, a partir da década de 1940, com o incremento tecnológico da produção.

A produção de lã, por meio da criação de raças laneiras e mistas, foi o principal objetivo da exploração econômica da ovinocultura no século XX. Os sistemas produtivos eram desenvolvidos com $\mathrm{o}$ intuito de se obter a maximização da produção de lã nos rebanhos, enquanto a produção de carne, produto considerado secundário, apenas supria o consumo dos estabelecimentos rurais.

O período de crise na atividade surgiu no final da década de 1980 em conseqüência dos elevados

ICurso de Pós-graduação em Extensão Rural, Universidade Federal de Santa Maria (UFSM), 97105-900. Santa Maria, RS, Brasil. Email: joaogaribaldi@brturbo.com.br. Autor para correspondência.

IIDepartamento de Educação Agrícola e Extensão Rural, UFSM, Santa Maria, RS, Brasil. 
estoques australianos de lã e do início da comercialização de tecidos sintéticos no mercado têxtil internacional. A crise se estendeu durante a década de 1990, o que fez muitos produtores desistirem da atividade, reduzindo significantemente o rebanho comercial e gerando a desestruturação de toda a cadeia produtiva (BOFILL, 1996; NOCCHI, 2001).

Entretanto, o aumento do poder aquisitivo da população e o incremento do abate de animais jovens trouxeram um novo mercado para a ovinocultura. A carne ovina começou a ser apreciada, levando a uma maior demanda de consumo, o que indica um excelente potencial para se tornar um produto substituto no mercado. Esse novo cenário possibilitou o início da reestruturação da ovinocultura no Rio Grande do Sul, com a transição do sistema produtivo laneiro para o sistema de produção de cordeiros para abate, tornandose, dessa forma, o produto carne a principal exploração econômica.

A sazonalidade produtiva da atividade, a inexistência de um mercado constante, a exigência de uma oferta regular de animais, a necessidade de escala para comercialização e a busca por animais jovens por parte dos frigoríficos são dificuldades enfrentadas pelos produtores na comercialização de animais para abate via mercado.

Na comercialização dos produtos derivados da ovinocultura, existem custos de produção implícitos para que a lã e a carne produzida sejam transacionadas para a indústria, até resultar no produto processado para o consumo. Assim, a análise econômica pode apontar os principais itens de custos da atividade, orientando as pesquisas tecnológicas de produção para o resultado econômico. A definição de uma escala mínima adequada pode ser apontada. A redução da incerteza e da assimetria das informações pode viabilizar algum tipo de contrato que melhore a coordenação da cadeia (GECOMP, 2004).

O estudo dos custos é um referencial teórico importante, resultado, sobretudo, do trabalho dos economistas pertencentes à Escola Neoclássica, devendo ser utilizado de forma conjunta ao estudo mais amplo do sistema produtivo em que a propriedade está inserida (ARBAGE, 2000).

A inserção da análise de custos no contexto do agronegócio é imprescindível para a expansão da sua competitividade, tanto no mercado interno, quanto no externo. A aplicação de um sistema de custos simplificado para as empresas agroindustriais permitirá o acompanhamento dos valores e de todas as operações realizadas na propriedade, possibilitando a descoberta das causas para a obtenção de lucro ou prejuízo (CALLADO, 2005).
Assim, esses dados demonstram a importância da análise econômica nas atividades rurais, sobretudo, a carência de estudos aplicados à ovinocultura. Portanto, o objetivo do presente trabalho é verificar os principais itens de custos, os custos de produção e a rentabilidade da produção ovina na Metade Sul do Rio Grande do Sul.

\section{MATERIAL E MÉTODOS}

O princípio metodológico do estudo de caso foi aplicado a fim de avaliar a situação econômica da produção ovina em sistemas de produção extensivos, de raças mistas, na Metade Sul do Rio Grande do Sul. Para YIN (2005), o estudo de caso, como estratégia de pesquisa, possibilita contribuir com o conhecimento de fenômenos individuais, organizacionais, políticos e de grupos. Dessa forma, buscaram-se produtores nos municípios de São Gabriel, Santana do Livramento e Dom Pedrito interessados em realizarem a análise econômica da produção ovina. Assim, participaram do estudo sete propriedades, sendo denominadas propriedades 1, 2 e 3 as localizadas em Dom Pedrito, propriedade 4 a localizada em Santana do Livramento e as propriedades 5, 6 e 7 localizadas em São Gabriel. As propriedades aliam as atividades de bovinocultura de corte e ovinocultura de ciclo completo, sendo as raças ovinas criadas Ideal, Corriedale e Cruzas.

A análise econômica da produção teve a duração de 12 meses, compreendendo o período de agosto de 2006 a julho de 2007. Os dados mensais levantados consistem em todas as despesas contraídas, as receitas provenientes dos produtos comercializados e os valores referentes ao autoconsumo das propriedades no período analisado.

Foram realizados dois inventários patrimoniais (maquinário e benfeitorias) nas sete propriedades, sendo um no início e outro no fim do período em análise. Juntamente com o inventário patrimonial, foram realizados três inventários do rebanho ovino e bovino das propriedades: no início, na metade e no final do período de 12 meses. Os inventários foram realizados com a finalidade de calcular o custo fixo de depreciação de benfeitorias e máquinas e a evolução do rebanho ovino (capitalização ou descapitalização dos ativos fixos de produção). Todos os dados econômicos das propriedades analisadas foram tabulados em um programa computacional (CONTAGRI, 2002) e posteriormente exportados para planilhas eletrônicas a fim de mensurar os custos e os indicadores econômicos.

Os dados referentes às despesas das propriedades foram categorizados conforme a 
metodologia de custos da CONAB (2007), sendo divididos em custos variáveis (despesas diretas com a produção), custos fixos (conservação e depreciação de máquinas e benfeitorias), custo operacional (custos variáveis + custos fixos) e custo total (custo operacional + custo de oportunidade da terra e do capital).

Nas propriedades pecuárias em análise, a ovinocultura é desenvolvida concomitantemente com a bovinocultura de corte. Assim, os custos variáveis e custos fixos referentes às duas atividades foram rateados para a ovinocultura, utilizando-se o percentual de unidades animais (UA) ovinas sobre o total de UA da propriedade.

Os custos com pessoal (mão-de-obra) foram rateados conforme a participação do uso da mão-deobra com a atividade de ovinocultura. Cada produtor estipulou um valor percentual do uso de mão-de-obra referente aos ovinos conforme a intensidade dos manejos realizados com a espécie.

Após a tabulação de todos os valores mensais de receitas, despesas e produtos consumidos das propriedades no período analisado e a realização do rateio dos valores de custos para a ovinocultura, os dados foram desmembrados em indicadores econômicos para a análise de rentabilidade da produção ovina. Os indicadores econômicos utilizados, baseados na exemplificação de LAMPERT (2003), foram: Renda Bruta Total (RBT), Margem Bruta (MB), Renda Operacional Agrícola (ROA) e Margem Líquida (ML), conforme descritos nas equações a seguir. $\mathrm{RBT}=$ P.q

Sendo: $\mathrm{P}=$ preço líquido de venda; $\mathrm{q}=$ quantidade (kg) vendida e/ou consumida e/ou estocada.

A margem bruta (equação 2) representa a capacidade de a empresa rural remunerar os custos com a produção e manter estabilidade econômica de curto prazo.

$\mathrm{MB}=\mathrm{RBT}-\mathrm{CV}$ variáveis.

Sendo: $\mathrm{RBT}=$ renda bruta total; $\mathrm{CV}=$ custos

A renda operacional agrícola (equação 3) indicará se a propriedade tem capacidade para remunerar todos os custos de produção e manter sustentabilidade de longo prazo.

$\mathrm{ROA}=\mathrm{RBT}-\mathrm{CO}$ operacional.

Sendo: $\mathrm{RBT}=$ renda bruta total $; \mathrm{CO}=$ custo

A margem líquida (equação 4) é o indicador que representa a capacidade da empresa rural em remunerar os custos variáveis, os custos fixos e os custos de oportunidade da terra e do capital.

$\mathrm{ML}=\mathrm{RBT}-\mathrm{CT}$
Sendo: $\mathrm{RBT}=$ renda bruta total; $\mathrm{CT}=$ custo

total.

O custo de oportunidade do capital foi calculado por meio da obtenção do valor de $6 \%$ (rendimento médio da poupança) sobre o custo operacional. Já o custo de oportunidade da terra foi calculado a partir do valor de arrendamento médio do hectare destinado à produção ovina na localidade em que a propriedade está inserida.

\section{RESULTADOS E DISCUSSÃO}

A renda bruta total, que compreende todas as receitas com animais, receitas com a lã, produtos consumidos e estocados, variou entre $\mathrm{R} \$ 133,7$ e $\mathrm{R} \$ 187,9$ por hectare nas propriedades analisadas.

Os dados de RBT obtidos nas propriedades em análise são muito similares aos encontrados na simulação econômica realizada por VIANA \& SILVEIRA (2006), os quais apontam valores de receita bruta de R\$ 172,00 por hectare em sistemas de produção de ovinos de ciclo completo. A RBT obtida com a ovinocultura representa, nas propriedades que desenvolvem a bovinocultura de corte aliada à ovinocultura, de 11,50\% a 31,20\% de todas as receitas das empresas rurais. Esses dados demonstram que a ovinocultura, apesar de ser explorada de forma secundária, contribui de forma significativa para as receitas totais das propriedades pecuárias analisadas.

A carne se tornou o principal produto de comercialização da ovinocultura nos últimos anos; porém, nas propriedades analisadas, a carne participa, em média, com 54\% da RBT da exploração de ovinos, enquanto o produto lã com $46 \%$. Esses dados demonstram a importância do produto lã no sistema produtivo de raças mistas, gerando receitas significativas e contribuindo para os resultados econômicos positivos da exploração.

A parcela de representação de cada categoria de custos dentro do custo total está exemplificada na tabela 1 . Observa-se que os custos que mais impactam o setor produtivo são os custos variáveis e o custo de oportunidade da terra.

Os custos variáveis têm grande participação pelo fato de representarem todo o capital de giro da produção. Ao computar os custos de oportunidade, verifica-se que a renda do fator terra é preponderante para a formulação do custo total, ou seja, a terra é o ativo fixo que mais onera o sistema produtivo, visto que é o bem de maior valor patrimonial na produção pecuária.

Ao se incluir o custo total, atribuindo valores de custo de oportunidade no cálculo da 
Tabela 1 - Percentagem das categorias de custos (\%) em relação ao custo total nas propriedades em análise.

\begin{tabular}{llllllll}
\hline Propriedades & 1 & 2 & 3 & 4 & 5 & 7 & 51,9 \\
\hline Custo variável & 52,5 & 37,1 & 48,6 & 49,6 & 50,6 & 48,6 \\
Custo fixo & 7,6 & 14,5 & 15,4 & 10,5 & 6,1 & 10,4 \\
Custo op. capital & 3,2 & 2,2 & 2,9 & 3,0 & 3,1 & 3,1 \\
Custo op. terra & 36,7 & 46,2 & 33,1 & 36,9 & 40,2 & 34,6 \\
Custo total & 100,0 & 100,0 & 100,0 & 100,0 & 100,0 & 100,0 \\
\hline
\end{tabular}

Fonte: Dados da pesquisa.

rentabilidade da produção, todas as propriedades apresentaram valores negativos de margem líquida, visto o impacto do custo de oportunidade da terra sobre as outras categorias de custo. Dessa maneira, a melhor forma de avaliar se a propriedade rural terá sustentabilidade econômica a médio e longo prazo é analisar a composição do custo operacional. O custo operacional é composto do custo variável e do custo fixo. A participação dos grupos de custos sobre o custo operacional total está exemplificada na tabela 2.

Os custos variáveis representam grande parcela do custo operacional. As despesas diretas com o sistema produtivo ovino representam de $71,90 \%$ a $89,30 \%$ do custo operacional das propriedades. Constata-se que a ovinocultura demanda elevado capital de giro para sua exploração, o que traz a necessidade de serem obtidos retornos a curto prazo. As despesas com pessoal, representadas pela mão- de-obra permanente, e a despesa ocasional, representada pelos encargos sociais e serviços de esquila, compõem o grupo de custos com maior percentual sobre o custo variável. Dentro do custo com pessoal se destacam as despesas com a mão-deobra permanente, fator de produção indispensável no desenvolvimento da atividade, porém o fator mais oneroso.

Os custos com insumos também representam parcela significativa dos custos variáveis. A reestruturação do sistema produtivo ovino para a produção de cordeiros para abate necessitou de investimentos na produção, como maiores despesas em nutrição, controle sanitário e novos métodos de reprodução.

Os custos fixos são representados pelos gastos com máquinas e benfeitorias. A maior parcela dos custos fixos está na conservação e depreciação de

Tabela 2 - Percentagem das categorias e dos grupos de custos (\%) em relação ao custo operacional nas propriedades em análise.

\begin{tabular}{|c|c|c|c|c|c|c|c|}
\hline Custos / Produtores & 1 & 2 & 3 & 4 & 5 & 6 & 7 \\
\hline Custo insumos & 24,4 & 16,3 & 11,5 & 15,2 & 32,5 & 31,1 & 27,5 \\
\hline Custos gerais & 7,2 & 10,0 & 3,1 & 8,4 & 1,7 & 5,7 & 5,9 \\
\hline Custo pessoal & 40,0 & 41,9 & 57,8 & 40,4 & 50,3 & 44,1 & 48,0 \\
\hline MO permanente & 8,5 & 19,1 & 38,2 & 24,0 & 31,4 & 19,2 & 31,4 \\
\hline MO ocasional & 14,2 & 0,4 & 4,3 & 6,1 & 0,0 & 14,9 & 1,6 \\
\hline Encargo & 4,2 & 6,3 & 3,9 & 2,5 & 0,0 & 1,8 & 0,0 \\
\hline Serviços esquila & 9,0 & 15,0 & 3,6 & 7,8 & 14,2 & 8,2 & 5,0 \\
\hline Outros serviços & 4,1 & 1,1 & 7,8 & 0,0 & 4,7 & 0,0 & 10,0 \\
\hline Custo impostos & 2,0 & 3,7 & 3,6 & 1,3 & 4,8 & 0,0 & 0,0 \\
\hline Custo terra & 13,8 & 0,0 & 0,0 & 17,2 & 0,0 & 2,3 & 0,0 \\
\hline Custos variáveis & 87,4 & 71,9 & 76,0 & 82,5 & 89,3 & 83,2 & 81,4 \\
\hline Custo construções & 6,6 & 17,3 & 15,4 & 12,4 & 7,8 & 13,7 & 12,3 \\
\hline Conservação & 2,5 & 6,3 & 9,9 & 3,8 & 0,0 & 7,3 & 6,0 \\
\hline Depreciação & 4,1 & 11,0 & 5,5 & 8,6 & 7,8 & 6,4 & 6,3 \\
\hline Custo máquinas & 6,0 & 10,8 & 8,6 & 5,1 & 2,9 & 3,1 & 6,2 \\
\hline Conservação & 3,5 & 3,8 & 7,1 & 2,3 & 0,0 & 0,6 & 2,7 \\
\hline Depreciação & 2,5 & 7,0 & 1,5 & 2,8 & 2,9 & 2,5 & 3,5 \\
\hline Custo fixo & 12,6 & 28,1 & 24,0 & 17,5 & 10,7 & 16,8 & 18,5 \\
\hline Custo operacional & 100,0 & 100,0 & 100,0 & 100,0 & 100,0 & 100,0 & 100,0 \\
\hline
\end{tabular}

Fonte: Dados da pesquisa.

Ciência Rural, v.39, n.4, jul, 2009. 
construções. Esses gastos são elevados, tendo em vista a necessidade de freqüentes manutenções das benfeitorias por parte dos produtores. Dentre elas, a manutenção de aramados, mangueiras e bretes são as principais despesas com construções. A conservação e a depreciação de máquinas também estão presentes, porém em menor percentual, representadas pela manutenção de implementos agrícolas, responsáveis pela conservação do campo nativo, pelo preparo e pela implementação de pastagens. Para se demonstrar os valores de rentabilidade, estão descritos na tabela 3 os indicadores de margem bruta, renda operacional agrícola e margem líquida.

A margem bruta foi positiva em todas as propriedades analisadas, ou seja, os ovinocultores remuneraram todos os custos diretos com a produção. A bovinocultura de corte na Metade Sul do Estado apresenta valores de margem bruta anual por hectare de R \$ 54,00 (SENAR/FARSUL/SEBRAE, 2005). Este é um bom parâmetro para se avaliar a condição econômica da ovinocultura, já que a atividade é uma exploração concorrente.

O custo operacional é o custo que uma atividade deve remunerar para que o produtor continue na atividade, obtendo estabilidade. Os resultados de ROA são positivos, exceto para propriedade 6 devido à venda de matrizes de descarte e à compra de ovelhas para reposição, o que elevou seu custo operacional. A ROA positiva mostra que as propriedades conseguem cobrir os custos fixos e variáveis e obter relativa lucratividade. Assim, as propriedades estão cobrindo os custos operacionais e se capitalizando. Esses dados confirmam que a ovinocultura é uma atividade rentável.

Além de ser uma atividade rentável, a integração da ovinocultura com a bovinocultura de corte possibilita uma série de vantagens em relação à produção única, tais como a obtenção de distintas fontes de renda em diferentes períodos, favorecendo a distribuição de receitas ao longo do ano, a redução dos custos fixos da propriedade, a redução da infestação parasitária dos rebanhos e o menor risco frente às flutuações de preços de uma atividade única.

Em relação à margem líquida, todas as propriedades apresentaram saldo negativo. Ao computar os custos de oportunidade, a RBT não apresenta condições de sobrepor o custo total, assim, dificilmente a exploração ovina terá capacidade de remunerar os custos de oportunidade.

\section{CONCLUSÃO}

Evidenciou-se, a partir da análise econômica da produção ovina, que a ovinocultura é uma atividade rentável a médio prazo. Essa rentabilidade é determinada pelo saldo positivo da renda operacional agrícola. A renda bruta total das propriedades em análise foi composta pela venda de ovinos e lã, bem como pelo consumo interno e pelo estoque formado no período corrente. A maior parcela da renda foi com as vendas de animais, porém a comercialização de lã apresentou parcela significativa da receita total. Os custos variáveis e os de oportunidade foram as categorias de custo que mais impactaram a formação do custo total. Dentro do custo operacional destacase o elevado custo com mão-de-obra, sendo o grupo que mais onera a produção ovina. Os custos com insumos também representam uma parcela significativa no custo operacional.

Os indicadores econômicos de margem bruta e renda operacional agrícola foram positivos, exceto na propriedade 6. Entretanto, a margem líquida apresentou valores negativos em todas as propriedades analisadas. O custo de oportunidade da terra foi o responsável pela elevação do custo total, o que levou ao saldo negativo do indicador. Assim, as propriedades têm capacidade de sustentar-se a médio e longo prazo, porém não remuneram os custos de oportunidade dos principais fatores de produção.

Tabela 3 - Margem bruta (MB), renda operacional agrícola (ROA) e margem líquida (ML) em reais (R\$) e seus respectivos valores em hectares nas propriedades em análise.

\begin{tabular}{|c|c|c|c|c|c|c|}
\hline Propriedades & MB & MB ha ${ }^{-1}$ & ROA & ROA ha ${ }^{-1}$ & ML & ML ha-1 \\
\hline 1 & $14.318,20$ & 52,80 & $9.804,00$ & 36,20 & $-13.872,90$ & $-51,20$ \\
\hline 2 & $22.277,30$ & 108,70 & $16.836,90$ & 82,10 & $-1.296,10$ & $-6,30$ \\
\hline 3 & $21.423,10$ & 79,00 & $12.110,40$ & 44,70 & $-9.774,30$ & $-36,10$ \\
\hline 4 & $5.086,70$ & 42,40 & $2.336,30$ & 19,50 & $-8.097,60$ & $-67,50$ \\
\hline 5 & $4.595,60$ & 35,30 & $3.019,90$ & 23,20 & $-8.230,90$ & $-63,30$ \\
\hline 6 & 365,60 & 4,90 & $-1.577,50$ & $-21,00$ & $-8.594,10$ & $-114,60$ \\
\hline 7 & $2.559,60$ & 29,80 & 484,50 & 5,60 & $-7.061,50$ & $-82,10$ \\
\hline
\end{tabular}

Fonte: Dados da pesquisa. 


\section{REFERÊNCIAS}

ARBAGE, A.P. Economia rural: conceitos básicos e aplicações. Chapecó: Universitária Grifos, 2000. 305p.

BOFILL, F.J. A reestruturação da ovinocultura gaúcha. Guaíba: Livraria e Editora Agropecuária, 1996. 137p.

CALlADO, A.A.C. Agronegócio. São Paulo: Atlas, 2005. 142 p.

CONAB. Metodologia de cálculo de custos de produção, 2007. Capturado em 20 jan. 2007. Online. Disponível na internet: http://www.conab.gov.br/conabweb/download/safra/ custosproducaometodologia.pdf

CONTAGRI. Software de gerenciamento agropecuário. Florianópolis: EPAGRI, 2002. (CD-ROM).

GECOMP. Análise econômica da ovinocultura no Distrito Federal. Brasília: Grupo de Estudos sobre a Competitividade e Sustentabilidade do Agronegócio. UnB, 2004. 83p. (Relatório final de pesquisa).
LAMPERT, J.A. Renda agrícola e avaliação de desempenho. In: LEAL, R.S. Administração rural. Santa Maria: UFSM, 2003. 121p.

NOCCHI, E.D. Os efeitos da crise da lã no mercado internacional e os impactos sócio-econômicos no município de Santana do Livramento - RS- Brasil. 2001. 71f. Dissertação (Mestrado em Integração e Cooperação Internacional) - Universidad Nacional de Rosario, Rosario, Argentina.

SENAR/FARSUL/SEBRAE. Diagnóstico de sistemas de produção de bovinocultura de corte do estado do Rio Grande do Sul. Porto Alegre: IEPE, 2005. 265p.

VIANA, J.G.A.; SILVEIRA, V.C.P. Ovinocultura no bioma campos: uma alternativa econômica. In: REUNIÃO DO GRUPO TÉCNICO EM FORRAGEIRAS DO CONE SUL, 21., 2006, Pelotas, RS. Anais... Pelotas: EMBRAPA, 2006. (CDROOM).

YIN, R.K. Estudo de caso: planejamento e métodos. Porto Alegre: Bookman, 2005. 212p. 